\title{
EDITORIAL
}

\section{You say goodbye, and I say hello!}

\author{
Marc Humbert
}

A S outgoing Chief Editor of the European Respiratory Review (ERR), I am delighted to be able to share with you some facts and thoughts in this farewell editorial. Over the last $4 \mathrm{yrs}$, the new ERR has grown and matured thanks to the leadership of an international editorial board and the outstanding support of the Publications Office. In this new era for the $E R R$, our aim was to further enhance scientific content and to form and develop strong links with the flagship publication of the European Respiratory Society (ERS), the European Respiratory Journal (ERJ), in order to establish the $E R R$ as a companion to the ERJ, without providing competition with the other ERS publications (European Respiratory Monograph and Breathe) [1]. In 2009, the format of the ERR was significantly restructured and the important decision was made to publish sponsored content, as well as spontaneously submitted original material $[2,3]$. Importantly, all the articles comprising this new format for the ERR have undergone peer review so that the highest scientific standards are maintained. The past 4 yrs have allowed us to be at the forefront of respiratory clinical education and research with cutting-edge publications in various fields ranging from common diseases that represent a major burden to respiratory health (such as asthma [4-8], chronic obstructive pulmonary disease [9], respiratory infections, tuberculosis [10], sleep-related disorders, venous thromboembolic disease and lung cancer), to much rarer but challenging conditions (including pulmonary hypertension [11, 12] and interstitial lung diseases [13-15]). In addition, regular editorials, updates, case reports, correspondences and book reviews have highlighted the dynamism of international pulmonary research, education and care [16]. The $E R R$ was recently accepted for indexing in Medline and our open-access strategy has allowed better visibility and dissemination of articles. Indeed, all ERR articles are freely available to all web users, as the website on which they are hosted is open access, http://err.ersjournals.com (figs 1 and 2).

As a result of this strategy, the ERR readership is now truly global with a large European and international exposure in North and Latin America, Asia, Oceania and Africa (table 1).

Contributing to the success of such an interesting journal has been truly satisfaction. My satisfaction is even greater as I

Univesité Paris-Sud, AP-HP, Service de Pneumologie, Hôpital Bicêtre, Inserm U999, Le Kremlin Bicêtre, France.

CORRESPONDENCE: M. Humbert, Service de Pneumologie, Hôpital Bicêtre, Assistance Publique Hôpitaux de Paris, 78 rue du Général Leclerc, 94270 Le Kremlin Bicêtre, France. E-mail: marc.humbert@bct.aphp.fr

PROVENANCE: Submitted article, peer reviewed.

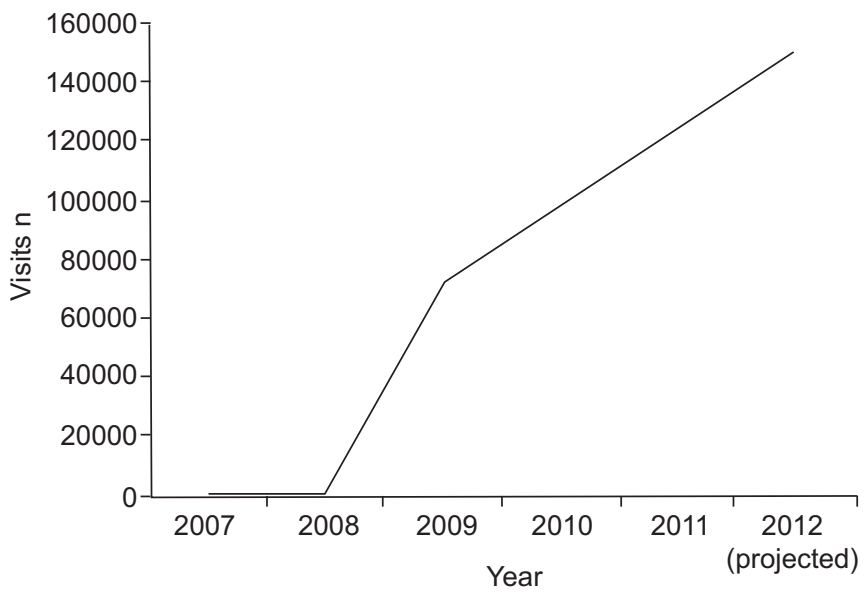

FIGURE 1. Overall number of visits to the European Respiratory Review website from 2007 to 2012 (projected).

announce that the incoming Chief Editor will be our friend and colleague Vincent Cottin from the University of Lyon (Lyon, France), former chair of the ERS Clinical Assembly and Associate Editor of the ERJ and ERR. With his accomplishment and the help of the Publications Office and a new editorial board, I am confident that the ERR will be even more successful. Importantly, an application will be made in the near future for the ERR to obtain and be included in the set of journals eligible for an impact factor. Once achieved, this will

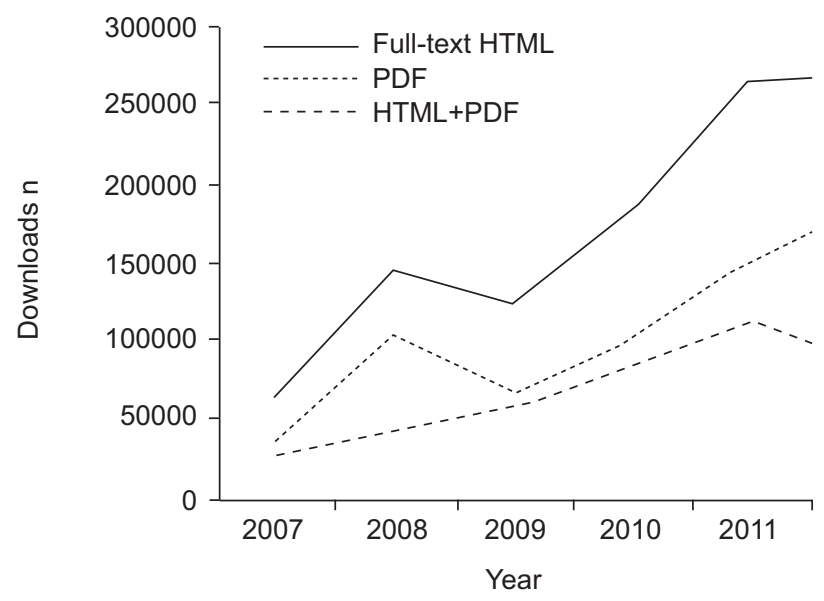

FIGURE 2. Number of downloaded European Respiratory Review articles (fulltext HTML, PDF and combined) from 2007 to 2011. 


\begin{tabular}{ll}
\hline TABLE 1 & $\begin{array}{l}\text { Visitors to the European Respiratory Review } \\
\text { website between October 1, } 2007 \text { and October 1, } \\
\text { 2012 according to country }\end{array}$ \\
\hline Country & Total visits n \\
\hline USA & 126021 \\
UK & 53645 \\
India & 24489 \\
Australia & 16096 \\
Canada & 14184 \\
Italy & 11510 \\
China & 10704 \\
Germany & 9562 \\
Spain & 7924 \\
Brazil & 7531 \\
Japan & 7256 \\
Philippines & 6997 \\
France & 6993 \\
Indonesia & 6909 \\
Switzerland & 6331 \\
Egypt & 5526 \\
Mexico & 4817 \\
The Netherlands & 4584 \\
Malaysia & 4545 \\
Greece & 3839 \\
\hline & \\
\hline
\end{tabular}

definitively establish the ERR as a key journal in the field of respiratory medicine.

On a more personal note, I am happy to announce that from January 2013 I will be taking on the mandate as the new ERJ Chief Editor. On this occasion, I will tighten the links between the ERJ and the ERR and will thus have the privilege to stay close to the ERR. As the Beatles sang: You say goodbye, and I say hello! [17].

\section{STATEMENT OF INTEREST}

M. Humbert has relationships with drug companies including Actelion, Aires, AstraZeneca, Bayer, Bristol-Myers Squibb, GSK, Merck, Novartis, Nycomed, Pfizer, Stallergènes, TEVA and United
Therapeutics. In addition to being an investigator in trials involving these companies, relationships include consultancy service and membership of scientific advisory boards.

\section{REFERENCES}

1 Dinh-Xuan AT, Brusasco V, Jadwiga WA, et al. ERS publications: the flagship and the fleet. Eur Respir J 2012; 40: 535-537.

2 Humbert M. Introducing the new European Respiratory Review. Eur Respir J 2009; 33: 466-467.

3 Humbert M. More pressure on pulmonary hypertension. Eur Respir Rev 2009; 18: 1-3.

4 Maestrelli $\mathrm{P}$, Schlünssen V, Mason $\mathrm{P}$, et al. Contribution of host factors and workplace exposure to the outcome of occupational asthma. Eur Respir Rev 2012; 21: 88-96.

5 Vandenplas O, Dressel H, Nowak D, et al. What is the optimal management option for occupational asthma? Eur Respir Rev 2012; 21: 97-104.

6 Wilken D, Baur X, Barbinova L, et al. What are the benefits of medical screening and surveillance? Eur Respir Rev 2012; 21: 105-111.

7 Heederik D, Henneberger PK, Redlich CA. Primary prevention: exposure reduction, skin exposure and respiratory protection. Eur Respir Rev 2012; 21: 112-124.

8 Baur X, Aasen TB, Burge PS, et al. The management of workrelated asthma guidelines: a broader perspective. Eur Respir Rev 2012; 21: 125-139.

9 Alifano M, Cuvelier A, Delage A, et al. Treatment of COPD: from pharmacological to instrumental therapies. Eur Respir Rev 2010; 19: 7-23.

10 Migliori GB, D'Ambrosio L, Centis R. Tuberculosis: an ancient and evergreen disease. Eur Respir Rev 2011; 20: 69-70.

11 Jardim C, Hoette S, Souza R. Contemporary issues in pulmonary hypertension. Eur Respir Rev 2010; 19: 266-271.

12 Humbert M, Simonneau G, Rubin LJ. A decade of achievement in pulmonary hypertension. Eur Respir Rev 2011; 20: 215-217.

13 du Bois RM. Idiopathic pulmonary fibrosis: present understanding and future options. Eur Respir Rev 2011; 20: 132-133.

14 Harari S, Caminati A. Update on diffuse parenchymal lung disease. Eur Respir Rev 2010; 19: 97-108.

15 Harari S, Cottin V, Humbert M. Global effort against rare and orphan diseases. Eur Respir Rev 2012; 21: 171-172.

16 Hamzaoui A, Ottmani S. Practical approach to lung health: lung health for everyone? Eur Respir Rev 2012; 21: 186-195.

17 Hello, Goodbye. The Beatles, 1967. 